\title{
Hypocalcemia and Other Associated Peri and Early Post-partum Problems of Dairy Cows in North-Western Ethiopia
}

Takele Kassegn Adugna ( $\square$ takeleadu1980@gmail.com )

Hawassa University

Sefinew Mekonnen Alemu

University of Gondar

Wassie Abebe Molla

University of Gondar

Shewatatek Melaku

Bahir Dar University

Research article

Keywords: Hypocalcemia, peri-partum and early postpartum, reproductive problems, dairy cows, Northwestern Ethiopia.

Posted Date: October 11th, 2019

DOI: https://doi.org/10.21203/rs.2.15873/v1

License: (우 (i) This work is licensed under a Creative Commons Attribution 4.0 International License. Read Full License 


\section{Abstract}

Abstract: Background: Hypocalcemia is the most important metabolic problems commonly affect transition dairy cows. (Sub) clinical hypocalcemia also prone the cow to an increased risk of several transition period problems. The current cross sectional study was conducted from January 2018 to May 2018 to estimate prevalence and identify associated risk factors of hypocalcaemia and other peri- and early post-partum period problems of dairy cows in North-Western Ethiopia specifically: Bahir Dar, Debretabor and Gondar. Methods : Data of 1527 cows was collected by face to face interview from 288 dairy farmers by using a semi-structured questionnaire. Serum calcium level was measured from blood samples collected within 12-48 hours of calving from 88 cows that have given birth during the study period. Ordinary and mixed logistic regressions with random herd effect models were used to check the association between the variables. Results : Prevalence of peri- and early post-partum reproductive problems was $80.6 \%(232 / 288)$ and $30.1 \%(459 / 1527)$ at herd and cow level, respectively. At herd level, retention of fetal membrane had the highest prevalence $41.3 \%$ followed by clinical mastitis $34.7 \%$ and milk fever $25.3 \%$. Prevalence of the rest problems was dystocia $18.1 \%$, clinical metritis $17 \%$ and vaginal and uterine prolapse $6.6 \%$. At cow level, retention of fetal membrane $9.7 \%$, clinical mastitis $8.4 \%$, milk fever $5.6 \%$, dystocia $4.1 \%$, clinical metritis (4.3\%) and vaginal and uterine prolapse was $1.2 \%$. Subclinical hypocalcemia was confirmed in $26.1 \%$ (23/88) of cows. Herd size was significantly associated $(p<0.05)$ with peri- and early post-partum problems at herd level. Milk fever, retained fetal membrane, and clinical mastitis were significantly associated $(p<0.05)$ with milk yield and parity. Clinical metritis was significantly associated $(p<0.05)$ with parity. Subclinical hypocalcemia was significantly associated $(p<0.05)$ with milk yield, parity and body condition score. Conclusion : From this study the prevalence of (sub) clinical hypocalcemia was on the lower border of the intervals reported by most studies. One or more peri- and early post-partum clinical problems were occurred from one third of dairy cows in the study areas. Factors associated with (sub) clinical hypocalcemia are associated with some of peri- and early post-partum problems.

\section{Background}

Calcium (Ca) is a very essential mineral in mammals' life. Calcium is involved in bone formation, muscle contraction, nerve transmission, blood clotting, and in many other fundamental biological processes in the body and serves as a second messenger regulating the actions of many hormones [1]. Hence, it is of major importance that $\mathrm{Ca}$ concentration is regulated within a homeostasis range in animals. This regulation process involves a coordinated effort among the hormones [2]. Hypocalcemia is the term used to express the reduction of calcium in the blood below the normal range. Hypocalcemia is among the most important macro-mineral metabolic problems that affects transition dairy cows [3]. Normal blood Ca in the cow is $2.1-2.8 \mathrm{moll} / \mathrm{L}$. When the serum Ca level drops below $2.0 \mathrm{~mol} / \mathrm{L}$ it is defined as subclinical hypocalcemia. If the serum $\mathrm{Ca}$ concentration drops further to below $1.625 \mathrm{moll} / \mathrm{L}$ clinical hypocalcaemia (milk fever) will be precipitated [4].

The colostrum that produced from a dairy cow contains 1.7-2.3 $\mathrm{g}$ Ca per $\mathrm{kg}$ of milk and this results loss of 30 to $40 \mathrm{~g}$ of $\mathrm{Ca}$ each day from the cow [1]. Blood Ca concentration remarkably declines in dairy cows around calving, with the lowest concentrations occurring about 12 to 48 hours after calving. Thus, at the initiation of lactation, body of dairy cows experience negative Ca balance $[5,6]$. Blood samples obtained at this time can reveal the extent of hypocalcemia experienced by a dairy herd. At this time the body system needs a very tight 
hormonal regulation to maintain calcium homeostasis by resorbing from the bone and reducing excretion through the kidney [7].

During late pregnancy, the drain of Ca represents a significant increase in Ca demand for late fetal growth and physiological maintenance. The ability of the cow to replenish the plasma Ca pools is often below the requirement of the mammary gland for $\mathrm{Ca}$ [6]. To maintain Ca homeostasis after calving, at the start of lactation, Ca compensating mechanisms are activated [8]. These mechanisms involve a coordinated effort among the hormones 1,25-dihydroxyvitamin D3, parathyroid hormone (PTH) and calcitonin (CT) [9]. But large proportions of dairy cows are unable to meet this challenge and they exposed to clinical or subclinical hypocalcemia around calving $[5,6]$. Hypocalcemia increased with parity mostly up to parity 5 . Some studies stated that it can be up parity $6^{\text {th }}$ but after the 6 parity hypocalcaemia declines due to reduction of milk yield. For instance Reinhardt et al. [10] reported subclinical hypocalcemia prevalence as $25 \%, 41 \%, 49 \%, 51 \%, 54 \%$, and $42 \%$ for $1^{\text {st }}-6^{\text {th }}$ parity cows, respectively.

In western world, on average, $5 \%-10 \%$ of dairy cows succumb to milk fever, but some literature suggesting that, the incidence rate in individual herds can also reach up to $80 \%$ of calving cows [9]. The incidence of milk fever is higher in dairy cows with increased milk yield [11]. Ethiopian cows (both cross breed and local breed) are producing less milk than European exotic breeds so one can expect low prevalence of clinical hypocalcemia in Ethiopian cows. However, previous studies reported that the prevalence of clinical hypocalcemia in Ethiopia is higher than the average stated in the western world. For instance prevalence of $30 \%$ in Gondar [12], 27\% in Addis Ababa [13] and 17.5\% in Hawassa [14] were reported.

It is an established knowledge that cows with clinical hypocalcemia are also prone to an increased risk of several health problems such as mastitis, retained fetal membrane, metritis, dystocia, prolapse of vagina and uterus, abomasum displacement and immune insufficiency, particularly during the transition period $[6,15,16]$. Recently, researchers suggested that subclinical hypocalcemia is also an important disorder that may predispose to clinical hypocalcemia and in turn can be associated with the problems mentioned for clinical hypocalcemia. However Subclinical hypocalcemia is often does not get enough attention in the dairy industry. In Ethiopia, the breed of cows, milk yield, the feed and feeding and other management practices are different from Western countries. Therefore, subclinical hypocalcemia and transition period problems may have different factors. There are no published studies in Ethiopian dairy cows that identified factors associated with subclinical hypocalcemia and transition period problems. Thus identifying factors associated with subclinical hypocalcemia and other transition period problems is important to recommend appropriate prevention methods to hypocalcemia and other transition period problems.

\section{Objective}

\section{General objective}

To estimate the prevalence of (sub) clinical hypocalcaemia and other peri- and early post-partum period clinical reproductive problems and assess associated risk factors of (sub) clinical hypocalcaemia and other peri- and early post-partum period clinical reproductive problems in dairy cows in north-western Ethiopia.

\section{Specific objectives}


- To determine the prevalence of clinical hypocalcaemia and other peri- and early post-partum period clinical reproductive problems in dairy cows in north-western Ethiopia.

- To estimate prevalence of subclinical hypocalcaemia in dairy cows in north-western Ethiopia.

- To identify factors that associate with (sub) clinical hypocalcaemia and other peri- and early post-partum period clinical reproductive problems in dairy cows in north-western Ethiopia.

\section{Results}

\section{Farm Description}

From the total $288,86 \%$ of the respondents were males and $14 \%$ were females. The average herd size of the dairy farms was 11 cattle, varying from 2 to 55 cattle. Majority of the farms $(78.8 \%)$ practice intensive management. Table.1 summarizes the management systems, housing type source of water and feed used by participated herds.

Table.1: Management systems, housing types and source of feed and water of dairy farms in North-Western Ethiopia.

\begin{tabular}{|c|c|c|c|c|c|c|}
\hline \multicolumn{2}{|c|}{ Management variables } & \multirow{2}{*}{$\begin{array}{c}\text { Number of } \\
\text { herd }\end{array}$} & \multicolumn{4}{|c|}{ The three district } \\
\hline & & & $\begin{array}{c}\text { Bahir Dar } \\
\text { (\%) }\end{array}$ & $\begin{array}{c}\text { Debretabor } \\
\text { (\%) }\end{array}$ & $\begin{array}{l}\text { Gondar } \\
\text { (\%) }\end{array}$ & $\begin{array}{c}\text { Total } \\
(\%)\end{array}$ \\
\hline \multirow{3}{*}{$\begin{array}{l}\text { Production } \\
\text { system }\end{array}$} & Intensive & 227 & 76.6 & 72.9 & 86.9 & 78.8 \\
\hline & Semi-intensive & 33 & 14.5 & 18.6 & 13.1 & 11.5 \\
\hline & Extensive & 28 & 9 & 8.5 & 0 & 9.7 \\
\hline \multirow[t]{2}{*}{ Housing type } & Concrete floor & 212 & 63.4 & 59.3 & 67.9 & 73.6 \\
\hline & Soil floor & 76 & 36.6 & 40.7 & 32.1 & 26.4 \\
\hline \multirow[t]{3}{*}{ Water source } & Pipe water & 192 & 55.2 & 69.5 & 86.9 & 66.7 \\
\hline & River water & 71 & 44.8 & 0 & 0 & 24.7 \\
\hline & Spring water & 25 & 0 & 30.5 & 13.1 & 8.7 \\
\hline \multirow[t]{7}{*}{ Feed source } & Grazing & 61 & 23.4 & 27.1 & 13.1 & 21.2 \\
\hline & Crop residue & 186 & 72.4 & 69.5 & 66.7 & 64.6 \\
\hline & Hay & 288 & 100 & 100 & 100 & 100.0 \\
\hline & $\begin{array}{l}\text { Milling by } \\
\text { product }\end{array}$ & 278 & 100.0 & 100 & 88.1 & 96.5 \\
\hline & $\begin{array}{l}\text { Legume by } \\
\text { product }\end{array}$ & 108 & 49.7 & 23.7 & 26.2 & 37.5 \\
\hline & Oil cake & 101 & 39.3 & 30.5 & 31 & 35.1 \\
\hline & $\begin{array}{l}\text { Brewery by } \\
\text { product }\end{array}$ & 79 & 0 & 0 & 94 & 27.4 \\
\hline
\end{tabular}

\section{Herd Level Peri- and Early post-partum Problems Prevalence and their Associated Risk Factors}

One or more of peri- and early post-partum problems occurred in majority (80.6\%) of the farms. Retention of fetal membrane occurred at the highest prevalence (41.3\%) followed by clinical mastitis (34.7\%). Prevalence of peri- and early post-partum problems are summarized in Fig (1). 
In univariable logistic regression analysis, production system was significantly associated with the prevalence of milk fever, metritis and mastitis; water source was significantly associated with the prevalence of milk fever, retention of fetal membrane, metritis and mastitis and herd size was significantly associated with the prevalence of all identified peri- and early post-partum problems except vaginal and uterine prolapse (Table.2). Since the production system and water source were significantly correlated $(p<0.05)$, only the production system and herd size were tested for the second model (multivariate logistic regression model) and herd size become the only variable that associates with peri- and early postpartum problems. The occurrence of the periand early postpartum problems increases by the odd of 1.1 for milk fever, retention of fetal membrane, clinical metritis, clinical mastitis and dystocia with the increment of the herd size by one unit. No confounding variables were found.

Table.2: The Herd level univariable logistic regression model between managemental factors and peri- and early post-partum problems in dairy cows in North-Western Ethiopia. 
Peri- and early post-partum problems

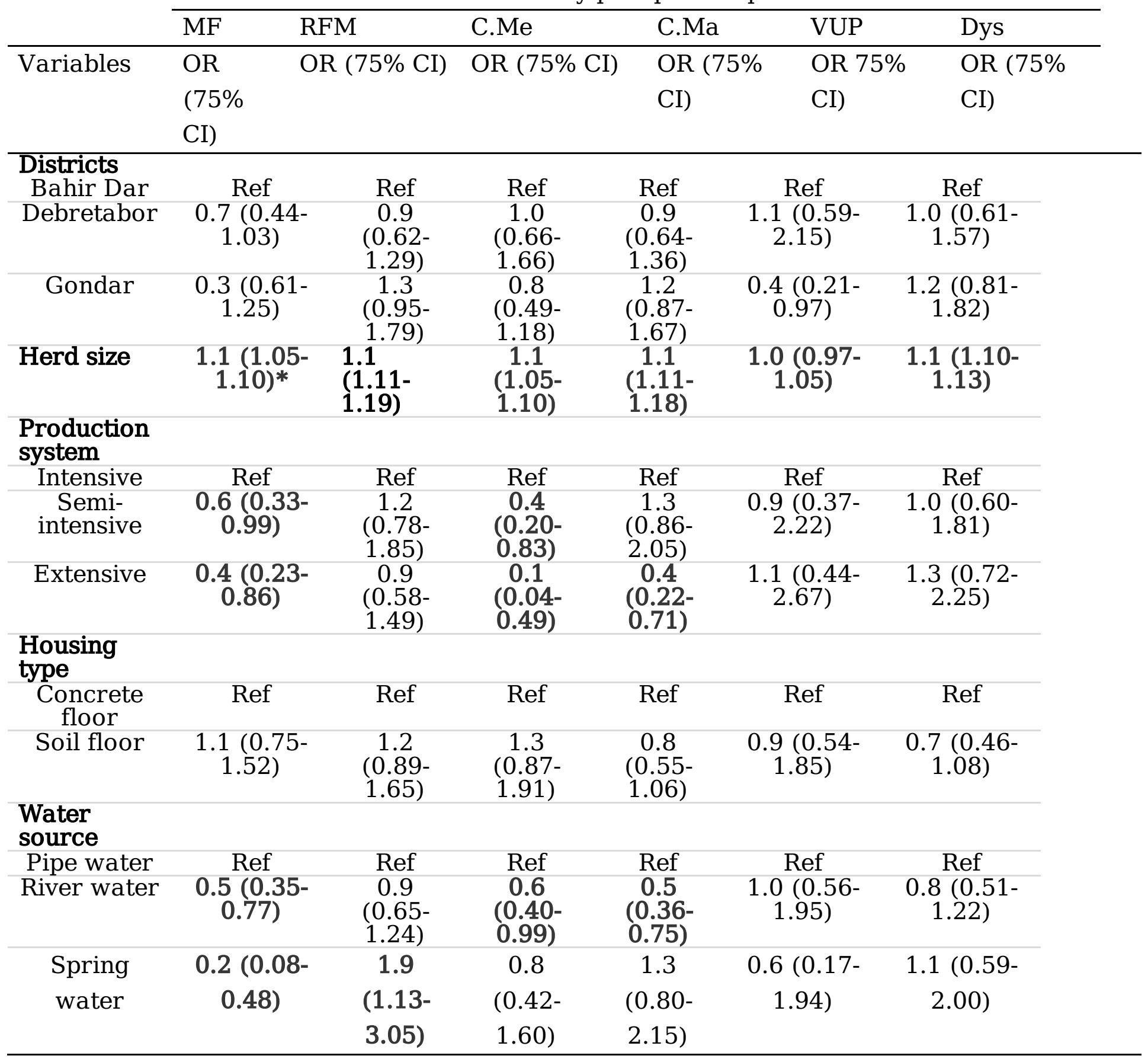

$\mathrm{OR}=$ Odds Ratio, $\mathrm{MF}=$ Milk Fever, $\mathrm{RFM}=$ Retention of Fetal Membrane, $\mathrm{C} . \mathrm{Me}=$ Clinical Metritis, C.Ma=Clinical Mastitis, VUP = Vaginal and Uterine Prolapse, Dys $=$ Dystocia, $\mathrm{Ref}=$ Reference, $\mathrm{CI}=$ Confidence Interval: $75 \%=$ Confidence Level, $*=$ all bolded results are significant

Cow level peri-partum and early post-partum problems prevalence and their associated risk factors

Of the total 1527 cows obtained from 288 herds, 459 (30.1\%) cows have shown peri- and early post-partum problems. The different peri-partum and early post-partum problems recorded in the study is summarized in 
Table.3.

Table.3: Cow level prevalence of peri-partum and early post-partum problems in dairy cows in NorthWestern Ethiopia

\begin{tabular}{|c|c|c|c|c|c|c|c|c|c|}
\hline \multirow[b]{2}{*}{ Variables } & \multirow[b]{2}{*}{ NC } & \multicolumn{8}{|c|}{ Peri-partum and early post-partum problems } \\
\hline & & MF (\%) & RFM (\%) & C.Me (\%) & C.Ma (\%) & VUP (\%) & Dys (\%) & Mix (\%) & Total (\%) \\
\hline \multicolumn{10}{|l|}{ Breed } \\
\hline local & 170 & 0 & 1.8 & 1.2 & 1.8 & 0.6 & 2.4 & 0 & 7.6 \\
\hline cross & 1357 & 5.6 & 10.7 & 4.6 & 9.2 & 1.1 & 4.3 & 3.2 & 32.9 \\
\hline \multicolumn{10}{|l|}{ Parity number } \\
\hline $1 \& 2$ & 380 & 1.1 & 3.9 & 2.4 & 3.9 & 0 & 6.8 & 1.3 & 16.8 \\
\hline $3 \& 4$ & 510 & 6.2 & 9.2 & 4.3 & 9.6 & 1 & 3.3 & 3.3 & 30.2 \\
\hline $5 \& 6$ & 452 & 8.6 & 14.2 & 5.9 & 10.3 & 2 & 3.3 & 3.3 & 39.6 \\
\hline $7 \&$ above & 185 & 5.9 & 11.9 & 5.9 & 10.3 & 2.7 & 2.2 & 3.8 & 34.1 \\
\hline \multicolumn{10}{|l|}{ Milk yield } \\
\hline$<10 \mathrm{~kg} /$ day & 533 & 0.4 & 3.8 & 2.3 & 1.9 & 0.2 & 4.2 & 0.8 & 10.9 \\
\hline 10 to $20 \mathrm{~kg} /$ day & 925 & 7.9 & 11.9 & 4.6 & 12.7 & 1.5 & 4 & 3.9 & 38.4 \\
\hline$>20 \mathrm{~kg} /$ day & 69 & 15.9 & 26.1 & 14.5 & 7.2 & 5.8 & 4.3 & 5.8 & 66.7 \\
\hline \multicolumn{10}{|l|}{ Districts } \\
\hline Bahir dar & 775 & 6.1 & 8.9 & 4.1 & 7.6 & 1.4 & 3.7 & 2.6 & 28.9 \\
\hline Debretabor & 235 & 6 & 10.6 & 6.4 & 9.8 & 2.1 & 4.7 & 4.7 & 34.9 \\
\hline Gondar & 517 & 4.8 & 10.4 & 3.5 & 8.9 & 0.6 & 4.3 & 2.5 & 29.8 \\
\hline \multicolumn{10}{|l|}{ Production system } \\
\hline Intensive & 1239 & 6.1 & 11.2 & 4.4 & 10.3 & 1.2 & 3.8 & 2.9 & 34.5 \\
\hline Semi-intensive & 194 & 4.6 & 9.4 & 4.1 & 8.2 & 1.5 & 5.2 & 3.1 & 29.9 \\
\hline Extensive & 94 & 2.1 & 8.5 & 3.2 & 6.4 & 1.1 & 5.3 & 2.1 & 24.5 \\
\hline \multicolumn{10}{|l|}{ Housing type } \\
\hline Concrete Floor & 1036 & 6.2 & 9.3 & 4.4 & 8.5 & 1.4 & 4.1 & 3.1 & 30.3 \\
\hline Soil Floor & 491 & 4.5 & 10.6 & 3.9 & 8.1 & 1 & 4.1 & 2.4 & 29.7 \\
\hline \multicolumn{10}{|l|}{ Water source } \\
\hline Pipe water & 1111 & 6 & 13.3 & 4.2 & 10.4 & 1 & 3.7 & 3 & 34.8 \\
\hline River water & 281 & 6 & 9.6 & 3.9 & 8.6 & 0.2 & 4.3 & 2.5 & 28.5 \\
\hline Spring water & 135 & 1.5 & 9.3 & 5.2 & 6.4 & 0.1 & 6.7 & 3.0 & 30.0 \\
\hline Total & 1527 & 5.6 & 9.7 & 4.3 & 8.4 & 1.2 & 4.1 & 2.9 & 30.1 \\
\hline
\end{tabular}

$\mathrm{NC}=$ Number of Cows, $\mathrm{MF}=$ Milk Fever, $\mathrm{RFM}=$ Retention of Fetal Membrane, $\mathrm{C} . \mathrm{Me}=$ Clinical Metritis, C.Ma=Clinical Mastitis, VUP= Vaginal and Uterine Prolapse, Dys =Dystocia, Mix= mixed (more than one)

There was a slight difference in the prevalence of peri- and early post-partum problems between different groups. Prevalence of milk fever, retained fetal membrane and clinical mastitis were higher in intensive production system followed by semi-intensive and extensive production system. Prevalence of milk fever, retention of fetal membrane, clinical metritis, clinical mastitis and vaginal and uterine prolapse were higher in cows on higher parity number and with high milk production. Prevalence of all peri- and early post-partum problems were higher in cross breed than local breed. The frequency of peri- and early post-partum problems in 
local breed was very low and it doesn't fit for the regression model. Therefore breed had not tested as a factor for the current result. The frequency of vaginal and uterine prolapse was also very low and it had not tested by regression model (Table.3).

None of the tested managemental factors were associated with any of peri-partum and early post-partum problems (Table.4). Occurrence of peri- and early post-partum problems were significantly associated $(p<0.05)$ with milk yield, and number of parity. Milk fever was significantly associated $(p<0.05)$ with milk yield and parity number. No confounding variables were found.

Occurrence of clinical metritis was significantly associated with only milk yield $(p<0.05)$. Retention of fetal membrane and clinical mastitis significantly associated $(p<0.05)$ with milk yield and parity number. Dystocia was not significantly associated $(p>0.05)$ with any of the variables.

Retention of fetal membrane was occurred more likely on cows that had $\geq 3$ parity compared to cows that had less than $3^{\text {rd }}$ parity. It was also higher in cows that produces $10-20 \mathrm{~kg}$ milk/day and $>20 \mathrm{~kg}$ milk/day than cows that produce $<10 \mathrm{~kg}$ milk/day. Cows that were producing $>20 \mathrm{~kg}$ milk/day had more odds of clinical metritis than cows producing $<10 \mathrm{~kg}$ milk/day. Parity number and milk yield were significantly associated with mastitis $(p<0.05)$. Clinical mastitis had more odds in cows that produce milk $>10 \mathrm{~kg} /$ day than cows that produce $<10 \mathrm{~kg}$ of milk/day (Table.5).

Table.4: Mixed model univariable logistic regression between the cow level prevalence of periand early post-partum problems and different managemental and animal factors by including herd as random variable in dairy cows in North-Western Ethiopia. 


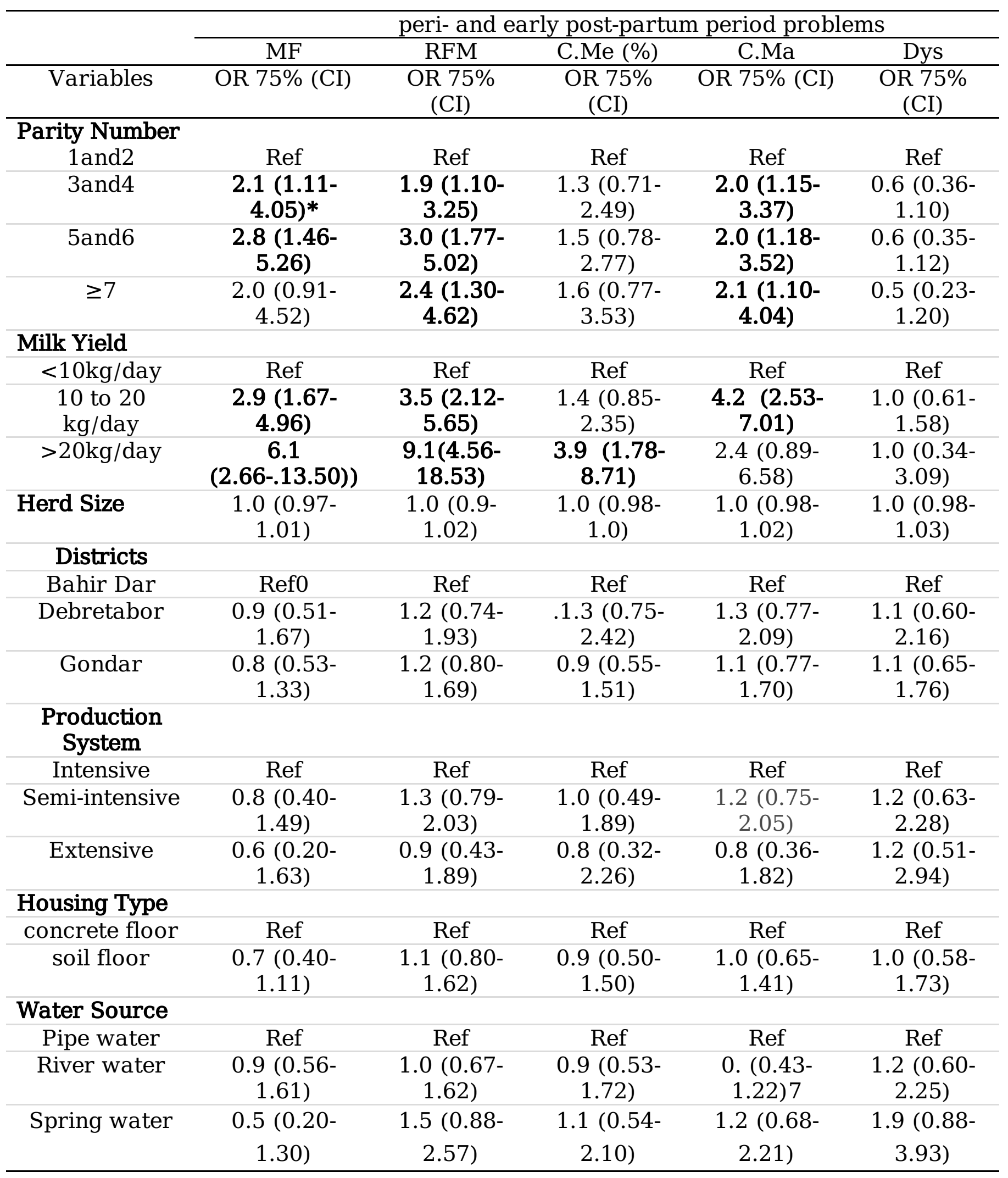

$\mathrm{MF}=$ Milk Fever, RFM= Retention of Fetal Membrane, C.Me= Clinical Metritis, C.Ma=Clinical Mastitis, Dys $=$ Dystocia, $\mathrm{OR}=$ Odds Ratio, $\mathrm{CI}=$ Confidence Interval, $75 \%=$ Confidence level, Ref $=$ Reference,$*=$ all bolded are significantly associated 
Table.5: The mixed model multivariable logistic regression between the cow level prevalence of peri- and early post-partum period problems and different management and animal factors by including herd as random variable in dairy cows in North-Western Ethiopia.

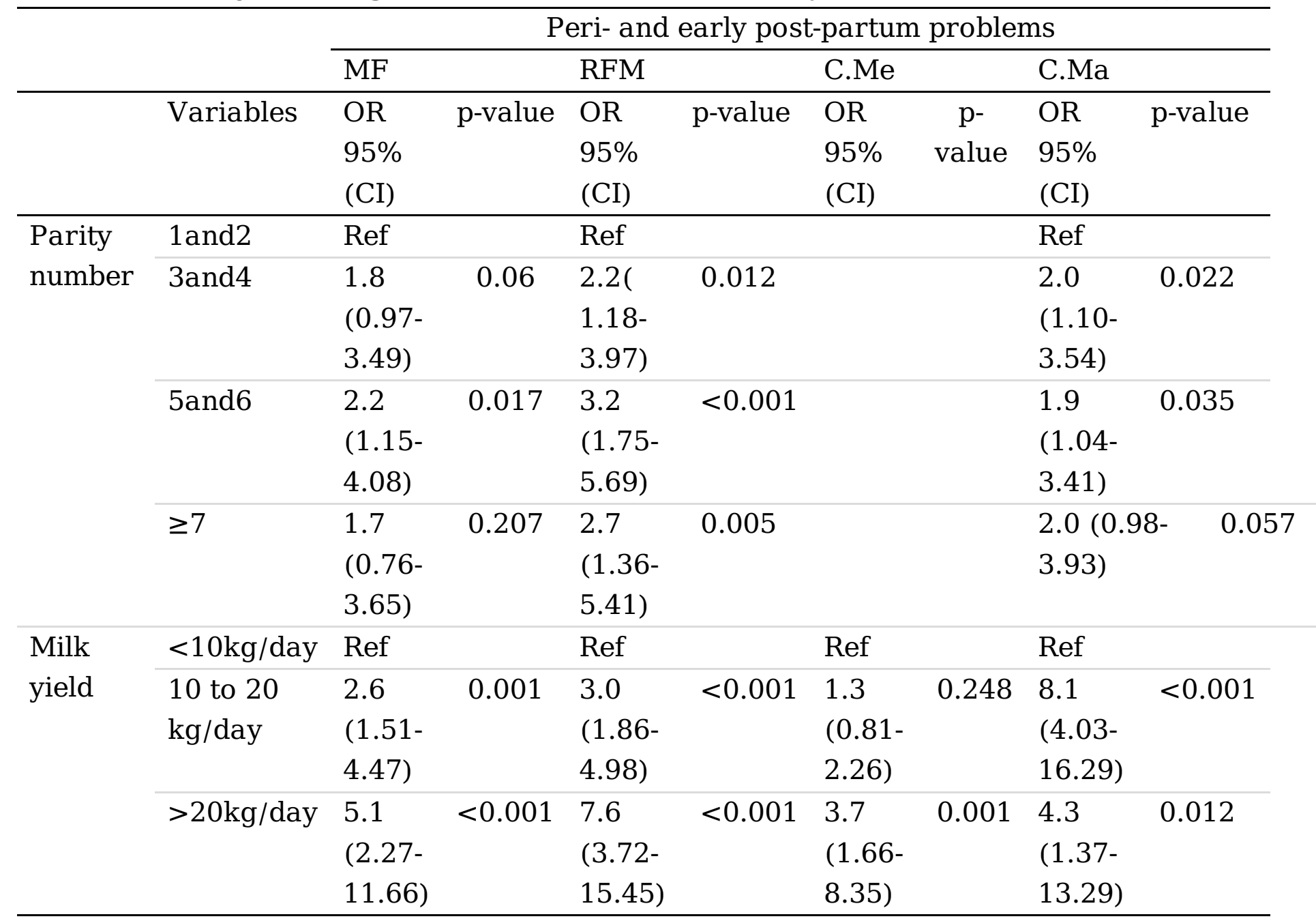

$\mathrm{MF}=$ Milk Fever, RFM= Retention of Fetal Membrane, C.Me= Clinical Metritis, C.Ma=Clinical Mastitis, OR= Adjusted Odds Ratio, $\mathrm{Cl}=$ Confidence Interval, 95\%=Confidence Level Ref $=$ Reference, $\mathrm{p}<0.05=$ statistically significant,

\section{(Sub) Clinical Hypocalcaemia Status and their Associated Risk Factors}

The mean serum calcium level of the 88 cows was $2.05 \mathrm{moll} / \mathrm{L}$ or $8.2 \mathrm{mg} / \mathrm{dl}$. Of the total animal examined, twenty three (26.1\%) were showed (sub) clinical hypocalcaemia. All of the (sub) clinical hypocalcaemia cases were detected in cross breed cows $(23 / 73=31.5 \%)$.

Milk yield, parity and body condition score were significantly associated $(\mathrm{p}<0.05)$ with subclinical hypocalcemia. The occurrence of (sub) clinical hypocalcaemia was increased by the odd of 1.1 times with the 
increment of milk yield by one kilogram. Cows on parity 5 and 6 were more likely suffered to (sub) clinical hypocalcaemia than cows on parity 1 and 2. Cows had fatty (4) and very fatty (5) body condition were more likely suffered to (sub) clinical hypocalcaemia than cows that had body condition below fatty (4) (Table.6).

Table.6: The univariable and multivariable logistic regression model (sub) clinical hypocalcaemia by serum Ca level and animal related factor in dairy cows in North-Western Ethiopia.

\begin{tabular}{|c|c|c|c|c|c|}
\hline & & & Univariate & Multivariate & \\
\hline Variables & Categories & $\begin{array}{c}\text { Hypocalcemia No } \\
(\%)\end{array}$ & OR 75\% (CI) & OR 95\% (CI) & $\begin{array}{c}\mathrm{P}- \\
\text { value }\end{array}$ \\
\hline Parity & 1and 2 & $3(8.3)$ & Ref & Ref & \\
\hline \multirow[t]{3}{*}{ Number } & 3 and 4 & $11(36.7)$ & $\begin{array}{l}6.1(1.50- \\
24.51)\end{array}$ & $\begin{array}{l}3.5(0.78- \\
15.86)\end{array}$ & 0.09 \\
\hline & 5 and 6 & $8(44.4)$ & $\begin{array}{l}8.4(1.86- \\
37.79)\end{array}$ & $6.7(1.25-36.13)$ & 0.027 \\
\hline & $\geq 7$ & $1(25)$ & $\begin{array}{c}3.5(0.27- \\
46.10) \\
\end{array}$ & $\begin{array}{c}1.0(0.07- \\
14.94)\end{array}$ & 0.98 \\
\hline Milk yield & & 26.1 & $1.2(1.05-1.26)$ & $1.1(1.01-1.23)$ & 0.035 \\
\hline BCS & $\begin{array}{l}2 \text {, and } 3 \\
4 \text { and } 5\end{array}$ & $\begin{array}{c}4(8.9) \\
19(44.2)\end{array}$ & $\begin{array}{c}\text { Ref } \\
7.8(2.37- \\
25.740\end{array}$ & $\begin{array}{c}\text { Ref } \\
6.6(1.75-24.96)\end{array}$ & 0.006 \\
\hline
\end{tabular}

BCS =Body Condition Score, CL: 95\%=95\% Confidence Level Ref= Reference, $p<0.05=$ statistically significant.

\section{Discussion}

The objective of this study was to estimate prevalence of (sub) clinical hypocalcaemia, peri- and early postpartum problems and to identify factors associated with (sub) clinical hypocalcaemia, and peri- and early postnatal problems in dairy cows in North-Western Ethiopia. The prevalence of clinical hypocalcemia estimated from the questionnaire data in the current study (5.6\%) was much lower than the prevalence reported in previous studies: $30 \%$, by[12] in Gondar, $27 \%$ by [13] in Addis Ababa and $17.5 \%$ by [14] in Hawassa dairy herds. This type of variation was supported by the result observed in the 135 controlled trials from the meta-analysis data set used by [17], for which the mean incidence was $21 \%$ with a range of $0-83 \%$. It was however, slightly lower than $8 \%$ reported by [18] from Zimbabwe. The prevalence of this study was moderately higher than the result reported in American 3. 5\% and Australian 3.45\% and somewhat lesser than the result $6.17 \%$ reported in European studies [9]. The typical prevalence of milk fever varies between $3.5 \%$ and $7.0 \%$ as reported by Mulligan and Doherty [19]. The lower prevalence in Western world possibly attributed with enhancements in nutritional management practices and better adaptations of these breeds with the climatic condition. However, it is difficult to reunite these variations given that Ethiopian herds produce less milk than Western herds. The frequency of metabolic disorders maybe influenced by climatic conditions [18]. The variation in the extent of UV radiation, regular evaporation rate and the variation between maximum and minimum ambient temperature may meaningfully disturb the occurrence of milk fever $[20,21]$.

The prevalence of peri- and early post-partum problems in dairy cows recorded in this study revealed that 232(80.6\%) of the herds and $459(30.1 \%)$ of the cows involved in the study were affected at least by one perior early postpartum problem. Because, to our experience, there is no previous study reported with similar period specific (only on peri-partum and within the first 21 day after caving) problems in Ethiopia, it was not possible 
to compare our results. From other countries, for instance, from Brazil, Peters et al [22] reported the prevalence of $45.6 \%$ and from Florida, Ribeiro et al [23] reported the prevalence of $37.5 \%$ clinical problems are higher than from the current result. This variation can be attributed with the spectrum of the problems included in the study, for instance, in our study only reproductive related problems were incorporated but Ribeiro et al [23] incorporated $2.5 \%$ respiratory, $4.0 \%$ digestive and $3.2 \%$ lameness.

Prevalence of retention of fetal membrane estimated in this study (9.7\%) was almost equivalent with prevalence reported in previous studies in Ethiopia (8.6\%) reported by Molalegn and Shiv [24], 7.18\% by Haile et al. [25] and $8.3 \%$ by Ayana and Gudeta [26], However, in other studies, retention of fetal membrane was reported with higher prevalence: $12.91 \%$ by Gizaw et al. [27], 14.28\% by Mamo [28], (17\%) by Haile et al. [25], $18.3 \%$ by Degefa et al. [29] and $19.2 \%$ by Gashaw et al. [30]. The variation in the prevalence of retention of fetal membrane between different studies may be attributed to the difference in predisposing factors to which the animals are subjected. Among factors, immune-suppression, vitamin and mineral deficiencies, and disease conditions (uterine paresis, abortion, stress, late or premature birth, dystocia, infections, and seasonal and hormonal disorders) have been identified as causes of retention of fetal membrane [31, 32].

The prevalence of clinical metritis estimated in the current study (4.3\%) was in agreement with the prevalence of clinical metritis reported by Dhaher et al.[33] who reported clinical metritis with prevalence of (4.0\%) and Hadush et al. [34] who reported clinical metritis with prevalence of 3.5\%. But, it was slightly lower than prevalence of clinical metritis reported by Ayana and Gudeta, [26] who reported prevalence of 5.6\%. These slight differences in prevalence of clinical metritis among studies may be related to differences in study methodology such as sampling and data collection, experience of farmers to clinical metritis. Prevalence of clinical metritis estimated in the current study and other previous studies are much lower than prevalence of clinical metritis reported from some other countries. For instance, from Brazil, Peters et al [22] reported prevalence of $17.3 \%$ from a study conducted on grazing dairy cows, Kim and Suh, (2003) reported 17.6\% from large confinement herds and Santos et al. [35] reported 16.1\%. However, a prevalence clinical metritis which almost equivalent to current study (5.3\%) was reported in a study conducted in Florida, USA by Ribeiro et al., [23]. These variations in prevalence of clinical metritis may be attributed to differences in diagnosis, breeds of cows, and difference in the frequency of observation of the cows and other transition management activities [36].

The prevalence of clinical mastitis that occurred during the first 21 days (3 week) after parturition was $8.4 \%$. This result was in agreement with Abuom et al. [37] having the prevalence of $9.7 \%$ in Keneya. It was slightly lower than the result reported in Brazile by Peters et al [22] in which an overall prevalence of $11.7 \%$ with herd level variations $19.1 \% 13.2 \% 10.2 \% \quad 14.3 \%$ and $13.3 \%$ in different farms reported.

It is not surprising that if prevalence of dystocia estimated in the current study $(4.1 \%)$ is in agreement with the prevalence of dystocia (3.4\%) reported by Benti and Zewdie [38] and 3.8\% by Gashaw et al., [30]. Because the methodology used by Benti and Zewdie [38] was similar with our study. Moreover, both studies were conducted in small holder Holstein Friesian and Zebu cross breed cows. However, prevalence lower or higher than prevalence in the current study was reported. Hadush et al. [34] reported prevalence of 2.9\%. Higher prevalence was also reported: $5.7 \%$ by Mamo, [28], $7.75 \%$ by Dawit and Ahmed [39] and 5.9\% by Haile et al. [25]. This variation in the occurrence of dystocia may be due to the fact that it is influenced by the factors such as parity 
of the dam, type of nutrition as well as breed of the sire. Inseminating cows with semen collected from large sized bulls without taking into account the size and age of cows is an important factor in precipitating dystocia [25]. In North-Western Ethiopia, dairy farmers are using Holstein Friesian semen to cross with indigenous Zebu cows for better milk yield. The indigenous Zebu cows are smaller in size compared to that of Holstein Friesian. So it is not surprising dystocia to be frequent in North-Western Ethiopian dairy farms. When dairy farmers are planning to cross breed their indigenous Zebu cows with Holstein Friesian semen, they should give priority to select cows and heifers which are larger in body size.

Prevalence of vaginal and uterine prolapse estimated in the current study was consistent with prevalence of vaginal and uterine prolapse reported by Dawite and Ahmed [39], Hadush et al. [34] and Benti and Zewdie [38]. But it was lower than prevalence of vaginal and uterine prolapse reported by Haile et al. [25]. However, prevalence of vaginal and uterine prolapse lower than in the current study were also reported: $0.65 \%$ by Bitew and Prasad [24], $0.5 \%$ by Gashaw et al. [30] and Woldegebriel [40] who reported $0.4 \%$. This variation might be due to management system (feeding), sample size and breed of animals.

Prevalence of subclinical hypocalcemia was $26.1 \%$. To my knowledge, there is no previous study reported on subclinical hypocalcemia in Ethiopia. However from other countries both lower and higher prevalence compared to the current study was reported. For instance, from Brazil, Peters et al [22] reported prevalence of $20 \%$ for subclinical hypocalcemia although a higher prevalence ( $40 \%)$ of subclinical hypocalcemia was reported by Ribeiro et al., [23] from the same country. Subclinical hypocalcemia was also reported at higher prevalence from other countries: $47.6 \%$ by Venjakob et al. [41] from German. Jawor et al. [42] reported an increased occurrence of subclinical hypocalcemia with parity: $41 \%, 49 \%, 51 \%, 54 \%$, and $42 \%$ in $2^{\text {nd }}-6^{\text {th }}$ lactation cows, respectively. The variation in prevalence of subclinical hypocalcemia may be attributed to the breed of cows related to milk yield, and the difference in the feeding management. Types of nutrition and milk yield of cows are risk to subclinical hypocalcemia [43]. In the current study, prevalence of subclinical hypocalcemia was not calculated for different parity cows.

The odds of peri- and post-partum problems specifically milk fever, retention of fetal membrane and clinical mastitis were higher in higher parity cows which was in agreement to other works conducted on general reproductive problems of dairy cows $[25,28,44]$. As literature supports this can be attributed to milk yield increment with parity and can be a risk of calcium deficiency because of the higher milk yield. Besides, parity increases with age and increment in age results decline of immunity of the cows. This leads pluriparus cows to be more prone to Peri-partum problems $[41,45]$. In addition, the genital tract of pluriparus cows repeatedly exposed to environmental factors and this can impart uterine infection [25].

The odds of peri- and early post-partum problems: milk fever, retention of fetal membrane, clinical mastitis and clinical metritis were significantly higher $(\mathrm{p}<0.05)$ in cows producing higher milk. Similar to our findings, Santos et al. [35] and Ribeiro et al. [23] had observed a high prevalence of clinical diseases in high-producing cows in confine farms. This attributed to loss of large amount of ionized calcium through milk which impairs muscular contraction and results milk fever and associated problems $[5,46,47]$. Moreover, higher amount of milk results in negative energy balance, and cause immune suppression $[8,48]$.

Prevalence of (Sub) clinical hypocalcemia was significantly higher $(\mathrm{p}<0.05)$ on cows produce higher milk yield. Similarly to the current finding, DeGaris \& Lean [9] and Caixeta et al. [47] had observed a high prevalence of 
hypocalcemia in high producing cows. This is attributed in two ways, one is loss of higher volume of calcium through milk and the second is high yielding cows also had a higher energy demand to support milk production and were more likely to acquire a severe energy deficiency after calving than cows with lower yields. This enforces the fat metabolism and develops ketosis that makes the cow anorexic and reduces dietary calcium intake [46].

The odd of (sub) clinical hypocalcemia was significantly higher $(p<0.05)$ in cows with higher parity (at 5 and 6 parity). This association was in agreement with the report stated by DeGaris \& Lean [9], Jawor et al. [42] and Reinhardt et al. [10]. The age and parity-associated susceptibility might be related to Ca homeostatic mechanisms. As reviewed by Seifi and Kia [45] with increasing age, the hemostasis process is impeded and results in moderate to severe hypocalcemia. It has been assumed that the number of vitamin $D$ receptors in intestines decline with increasing age. In addition, as animals age increase, the number of receptors for PTH on target tissues decline.

The occurrence of (sub) clinical hypocalcemia was significantly higher $(p<0.05)$ on cows with higher body condition. Similarly to this DeGaris \& Lean [9] reported a higher prevalence of hypocalcemia in cows with higher body condition. This is due to over conditioned dairy cows take small amount of calcium this is caused by reduced appetite and with higher BCS at calving have a higher calcium output in milk, making them more prone to hypocalcemia [49].

\section{Methods}

\section{Study Area}

The study was carried out at three sites in North-Western Ethiopia: Bahir Dar, Debretabor and Gondar. These areas are located between $11.29^{\circ}-13.8^{\circ} \mathrm{N}$ latitude and $35.7^{\circ}-38.017^{\circ} \mathrm{E}$ longitude with an altitude of $1,820-2706$ m.a.s.l., and have annual rain fall ranging from $1200-1600 \mathrm{~mm}$ and annual temperature from $9.9^{\circ} \mathrm{C}$ to $29.5^{\circ} \mathrm{C}$ [50-52]

\section{Study Design}

A cross sectional study was conducted from February 2018 to May 2018 to determine the prevalence of (sub) clinical hypocalcaemia and other peri- and early post-partum period clinical reproductive problems and identify associated risk factors of (sub) clinical hypocalcaemia and other peri- and early post-partum period clinical reproductive problems in dairy cows in north-western Ethiopia.

\section{Study Animals}

The study animals were private owned, cross Holstein Friesian or Jersey and local Zebu breed dairy cows. Most of these animals were managed under intensive production system. Few herds were managed by the semiintensive and extensive production systems. All the study herds were housed. The floor of the houses was either concrete or soil. The feed source of the study animals were roughage, hay and crop residue, and concentrate (Milling by products, legume byproducts, oil cake and brewery by products). Herds use pipe, river and spring for water sources. 


\section{Sample Size Determination for Questionnaire Survey}

Because there are no previous herd level studies, the sample size of the herd was determined by using prevalence from cow level studies of milk fever as expected prevalence, at $95 \%$ confidence level with $5 \%$ absolute precision. Prevalence of milk fever reported by three previous studies: $30 \%$ in Gondar [12] 27\% in Addis Ababa [13] and $17.5 \%$ in Hawassa [14] were averaged which become $25 \%$ and used as expected prevalence. The sample size was calculated using the formula from [53].

$$
n=\frac{1.96^{2} * p^{*}(1-p)}{d^{2}}
$$

Where:

$n=$ sample size

$p=$ expected prevalence

$d=$ desired absolute precision

Based on the calculation the herd sample size was 288 herds. Within the herds, every cow that spent a transition period in the participated herd was selected.

\section{Herd Selection and Sampling Method for the Questionnaire Survey}

The three study sites were selected purposively. The list of dairy farms considered in the study was obtained from Agricultural and Rural Development offices of the selected towns and from office of dairy cooperatives. Although random sampling was planned for the selection of herds, randomizing herds was hardly possible because of time, logistic and farmers' behavior. Therefore, the 288 participated herds were included in the study by farmers' willingness. Within the herds, data was collected from every cow that spent a transition period in the participated herd. In that way data was collected from 1527 dairy cows in 288 herds.

\section{Design of the Questionnaire and Data Collection}

Data was collected from dairy farmers by using a semi-structured questionnaire. The questionnaire was focused on major health challenges of dairy cows in peri- and early post-partum period in recent calving. The questionnaire included questions about breed of cow, present parity number, milk yield, and management history including feed type, water source, housing type, production system (extensive, semi-intensive and intensive type of management).

Peri- and early post-partum period problems data were collected based on the criteria described below

Peri-and early post-partum period problems. problems that occurred starting from stages of parturition to the first 21days after calving. 
Dystocia: when parturition was prolonged markedly for more than $6 \mathrm{hr}$ and the cow required assistance[54].

Retained fetal membranes: when the fetal membranes (placenta) are visibly hanged for $12 \mathrm{hr}$ or more after calving [55].

Milk Fever. if a cow displays clinical signs that include muscle weakness, nervousness, muscle shaking, cold ears, and eventually when a cow being unable to rise within 3 days of calving [55].

Clinical metritis. an abnormal (smelly and watery) uterine discharge within 21 days of calving characterized by reddish brown, white or whitish to yellow mucopurulent vaginal discharge [54].

Clinical Mastitis: visual observation of abnormal udder and milk from a quarter[55].

Uterine prolapse: coming out of uterus through the vulva commonly shortly after parturition and hanged out with the inner surface outer most [55].

Vaginal prolapse: protrusion of the vagina and sometimes with the cervix through the vulva [55].

\section{Blood Sample and Serum Ca Analysis for Subclinical Hypocalcemia}

Blood samples were collected from 88 (73 cross breed 15 local breed) cows that have given birth during the study period from the jugular vein within 12-48 hours after calving in the selected 288 herds. Blood samples were maintained at room temperature for one hour. After an hour the blood samples were centrifuged and serum harvested. The collected serum was frozen at $-20^{\circ} \mathrm{C}$ (Tuck et al., 2008) until further laboratory analysis was made. The 73 serum samples were analyzed for its calcium level at Felegehiot Referral Hospital and the rest 15 serum sample at Kidanemihiret Higher Clinic in Bahir Dar by using automated electrolyte analyzer (mind ray BS-120). Cows whose blood Ca level below $2 \mathrm{mmol} / \mathrm{L}(8 \mathrm{mg} / \mathrm{dL})$ were categorized as hypocalcemic.

Body condition score (BSC) for those cows that have given birth during the study period were scored in addition to factors stated on the questioner survey. BSC was recorded based on the criteria set by [56], which ranged from 1 to 5 BSC 1, 2, 3, 4, and 5 stands for cows with the very poor, poor, good, fat, and very fat body condition respectively.

\section{Data Analysis}

All data collected during the study period was checked, coded and entered in to Microsoft Excel spreadsheet and analyzed using SPSS software Version 20. In general, data analysis was followed a 3 step approach: (1) Descriptive statistics which included calculation of the prevalence, frequency and graphs. (2) Univariate analysis was done by using logistic regression to evaluate associations between a dependent variable and independent variables. Seven dependent variables were assumed: milk fever, retained fetal membrane, clinical mastitis, dystocia, vaginal and uterine prolapse and subclinical hypocalcemia. The independent variables were managemental variable (production system, water source, housing type and the three districts) and animal factors (breed, milk yield, and parity). Body condition score was also used as independent variable for subclinical hypocalcemia. Because cows were clustered within herds, the analysis was done using mixed logistic regression models with a random herd effect. (3) Multivariate logistic regression: risk factors that were statistically significant at $\mathrm{P}<0.25$ in the univariable analyses were tested in the same multivariable regression 
models. Variables in multivariable models with $\mathrm{P}<0.05$ were retained in the final model. Variables which were not significant at the multivariate model were checked for confounding effect.

\section{List Of Abbreviations}

$\mathrm{PTH}=$ parathyroid hormone, $\mathrm{CT}=$ Calcitonin, $\mathrm{OR}=$ Odds Ratio, MF= Milk Fever, RFM= Retention of Fetal Membrane, C.Me= Clinical Metritis, C.Ma=Clinical Mastitis, VUP= Vaginal and Uterine Prolapse, Dys =Dystocia, Ref= Reference, $\mathrm{Cl}=$ Confidence Interval, BCS =Body Condition Score, USA= United State of America, CVMAS= College of Veterinary Medicine and Animal Sciences

\section{Declarations}

\section{Ethical approval and consent}

The study was conducted after the protocol was ethically reviewed and approved with a written letter given by Research Ethical Review Committee of College of veterinary medicine and animal sciences (CVMAS) having the Ref. No, CVMAS: 553/07/2010. Dairy cow's owner permission was asked verbally to take a blood sample with full consent by explaining the objectives of the study because written consent is not necessary in this case and the research ethical review board had approved this protocol.

\section{Consent for publication}

Not applicable.

\section{Availability of data and materials}

The dataset supporting the conclusions of this article is included within the article and the datasets used and/or analyzed during the current study are available from the corresponding author on reasonable request.

\section{Competing interests}

The authors declare that they have no competing interests.

\section{Funding}

The fund for the preparing research proposal, sample collection, laboratory processing fee and writing the paper was covered by Bugina Woreda Animal resource development and health care office whereas the materials for sample collection and preservation in addition advising fees of the professors was obtained from and University of Gondar.

\section{Authors' contributions}

T.A developed research idea and conducted the main study. S.A and W.M supervised, commented and corrected the research protocol, data analysis and all the write-up processes. S.M had major contribution during data collection and laboratory investigation. All authors read and approved the final manuscript.

\section{Acknowledgements}


As per their contribution to this study, stuff members of Bugina Woreda Animal resource development and health care office and University of Gondar are acknowledged. The support of laboratory technicians of Bahir Dar Regional Veterinary Diagnostic and Investigation Center; and Agricultural and Rural Development officers of the three districts of the study areas (Bahir Dar, Debretabor and Gondar) and Andasa Livestock Research Center staff members for their provision of important documents/information and facilities are acknowledged.

\section{References}

1. Goff JP. Macromineral disorders of the transition cow. . Veterinary Clinics: Food Animal Practice,. 2004;20(3):471-94.

2. KIDA KN, pp. Use of every ten-day criteria for metabolic profile test after calving and dry off in dairy herds. Journal of veterinary medical science,. 2002;64(11):1003-10.

3. LeBlanc SJ, Lissemore KD, Kelton DF, Duffield TF, Leslie KE. Major advances in disease prevention in dairy cattle. ournal of dairy science, . 2006;89(4):1267-79.

4. Thirunavukkarasu M, Kathiravan G, Kalaikannan A, Jebarani W. Quantifying economic losses due to milk fever in dairy farms. Agricultural Economics Research Review. 2010;23(347-2016-17036):77-82.

5. Kimura K, Reinhardt T, Goff J. Parturition and hypocalcemia blunts calcium signals in immune cells of dairy cattle. Journal of dairy science. 2006;89(7):2588-95.

6. Goff JP, editor Transition cow immune function and interaction with metabolic diseases. Proc 17th Annu Tri-State Dairy Nutr Conf The Ohio State University, Columbus; 2008.

7. Goff JP. Calcium and magnesium disorders. Veterinary Clinics: Food Animal Practice. 2014;30(2):359-81.

8. Ferneborg S. Calcium homeostasis at calving in cows milked prepartum. 2010.

9. DeGaris PJ, Lean IJ. Milk fever in dairy cows: A review of pathophysiology and control principles. The Veterinary Journal. 2008;176(1):58-69.

10. Reinhardt TA, Lippolis JD, McCluskey BJ, Goff JP, Horst RL. Prevalence of subclinical hypocalcemia in dairy herds. The Veterinary Journal. 2011;188(1):122-4.

11. Sharma N. Economically important production diseases of dairy animals. SMVS Dairy Year Book-2010 Gurgoan, India: Sarva Manav Vikash Samiti. 2010:47-65.

12. Anteneh S, Guadu T, Fentahun T, Chanie M. Incidence of Milk Fever on Dairy Cows and its Risk Factors in Gondar Town, Northwest Ethiopia. International Journal of Natural Sciences. 2012;2(4):104-7.

13. Akalu A. Status of Parturient Paresis (Hypocalcaemia and Milk Fever) on Dairy Farm in Addis Ababa City. European Journal of Applied Sciences. 2017; 9(1):06-10.

14. Fasil N, Juta T. Major Health Challenges of Dairy Cattle in Hawassa Town SNNPRS, Ethiopia. Journal of Vet Sci Technol 2016 7(5):1-6.

15. McDowell LR. Recent advances in minerals and vitamins on nutrition of lactating cows. Pak J Nutr. 2002;1:8-19.

16. Roberts T, Chapinal N, LeBlanc S, Kelton D, Dubuc J, Duffield T. Metabolic parameters in transition cows as indicators for early-lactation culling risk. Journal of dairy science. 2012;95(6):3057-63. 
17. Lean I, DeGaris P, McNeil D, Block E. Hypocalcemia in dairy cows: meta-analysis and dietary cation anion difference theory revisited. Journal of dairy science. 2006;89(2):669-84.

18. Chiwome B, Kandiwa E, Mushonga B, Sajeni S, Habarugira G. A study of the incidence of milk fever in Jersey and Holstein cows at a dairy farm in Beatrice, Zimbabwe. Journal of the South African Veterinary Association. 2017;88(1):1-6.

19. Mulligan F, Doherty M. Production diseases of the transition cow. The Veterinary Journal. 2008;176(1):3-9.

20. Roche J, Berry D. Periparturient climatic, animal, and management factors influencing the incidence of milk fever in grazing systems. Journal of dairy science. 2006;89(7):2775-83.

21. Capper J, Cady R. A comparison of the environmental impact of Jersey compared with Holstein milk for cheese production. Journal of dairy science. 2012;95(1):165-76.

22. Peters M, Silveira I, Fischer V. Impact of subclinical and clinical mastitis on sensitivity to pain of dairy cows. Animal. 2015;9(12):2024-8.

23. Ribeiro E, Lima F, Greco L, Bisinotto R, Monteiro A, Favoreto M, et al. Prevalence of periparturient diseases and effects on fertility of seasonally calving grazing dairy cows supplemented with concentrates. Journal of Dairy Science. 2013;96(9):5682-97.

24. Molalegne B, Shiv P. Study on major reproductive health problems in indigenous and cross breed cows in and around Bedelle, South West Ethiopia. Journal of Animal and Veterinary Advances. 2011;10(6):723-7.

25. Haile A, Tsegaye Y, Tesfaye N. Assessment of major reproductive disorders of dairy cattle in urban and per urban area of Hosanna, Southern Ethiopia. environment. 2014;8:22.

26. Ayana T, Gudeta T. Incidence of Major Clinical Reproductive Health Problems of Dairy Cows at Bako Livestock Research Farm over a Two-Year Period (September 2008-December 2010). Ethiopia Anim Vet Sci. 2015;3(6):158-65.

27. Gizaw Y, Bekana M, Abayneh T. Major reproductive health problems in smallholder dairy production in and around Nazareth town, Central Ethiopia. Priory Medical Journal Online. 2007.

28. Mamo T. Study on major postpartum reproductive problems of smallholder dairy cows in and around Debre Zeit. DVM Thesis, FVM, AAU, DebreZeit, Ethiopia. 2004.

29. Degefu H, Mohamud M, Hailemelekot M, Yohannes M. Seroprevalence of bovine brucellosis in agro pastoral areas of Jijjiga zone of Somali National Regional State, Eastern Ethiopia. Ethiopian Veterinary Journal. 2011;15(1).

30. Gashaw A, Worku F, Mulugeta S. Assessment of Small Holder Dairy Production System and Their Reproductive Health Problems in Jimma Town, Southwestern Ethiopia. International Journal of Applied Research in Veterinary Medicine. 2011;9(1).

31. Akar Y, Yildiz H. Concentrations of some minerals in cows with retained placenta and abortion. Turkish Journal of Veterinary and Animal Sciences. 2005;29(5):1157-62.

32. Lotthammer K. Comparative studies of the course of mineral, metabolite, enzyme and hormone levels in blood serum ante partum in dairy cows with and without later retained placenta. DTW Deutsche tierarztliche Wochenschrift. 1983;90(10):427.

33. Dhaher NN, Hadree DH, Ismaeel MA, Noomi BS. COMMON CAUSES OF REDUCED FERTILITY IN COWS IN SOME DISTRICTS OF SALAH-ADDIN. Euphrates Journal of Agriculture Science. 2018;10(3):73-7. 
34. Hadush A, Abdella A, Regassa F. Major prepartum and postpartum reproductive problems of dairy cattle in Central Ethiopia. Journal of Veterinary Medicine and Animal Health. 2013;5(4):118-23.

35. Santos J, Bisinotto R, Ribeiro E, Lima F, Greco L, Staples C, et al. Applying nutrition and physiology to improve reproduction in dairy cattle. Reproduction in Domestic Ruminants VII. 2011:387-403.

36. Sheldon IM, Lewis GS, LeBlanc S, Gilbert RO. Defining postpartum uterine disease in cattle. Theriogenology. 2006;65(8):1516-30.

37. Abuom T, Njenga M, Wabacha J, Tsuma V, Gitau G. Incidence and risk factors of periparturient conditions in smallholder dairy cattle herds in Kikuyu Division of Kiambu District, Kenya. Ethiopian Veterinary Journal. 2012;16(2):85-102.

38. Benti AD, Zewdie W. Major reproductive health problems of indigenous Borena cows in Ethiopia. Journal of Advanced Veterinary and Animal Research. 2014;1(4):182-8.

39. Tesfaye D, Shamble A. Reproductive health problems of cows under different management systems in Kombolcha, Noetheast Ehiopia. Adv Biomed Res. 2013;7:104-8.

40. Weldegebriall B. Assessment of major reproductive problems of dairy cattle in selected sites of central Zone of Tigrai Region, northern Ethiopia: Mekelle Univeristy; 2015.

41. Venjakob P, Borchardt S, Heuwieser W. Hypocalcemia-Cow-level prevalence and preventive strategies in German dairy herds. Journal of dairy science. 2017;100(11):9258-66.

42. Jawor P, Huzzey J, LeBlanc S, von Keyserlingk M. Associations of subclinical hypocalcemia at calving with milk yield, and feeding, drinking, and standing behaviors around parturition in Holstein cows. Journal of dairy science. 2012;95(3):1240-8.

43. Martinez N, Risco C, Lima F, Bisinotto R, Greco L, Ribeiro E, et al. Evaluation of peripartal calcium status, energetic profile, and neutrophil function in dairy cows at low or high risk of developing uterine disease. Journal of dairy science. 2012;95(12):7158-72.

44. Micheal K. Major clinical reproductive problem of small holder dairy cows in and around Awassa. DVM Thesis, Addis Ababa University, Faculty of Veterinary Medicine, Debre Zeit, Ethiopia. 2003.

45. Seifı HA, Kia S. Subclinical Hypocalcemia in Dairy Cows: Pathophysiology, Consequences and Monitoring. Iranian Journal of Veterinary Science and Technology. 2018;9(2):1-15.

46. Mulligan F, O Grady L, Rice D, Doherty M. Production diseases of the transition cow: Milk fever and subclinical hypocalcaemia. Irish Veterinary Journal. 2006;59(12):697.

47. Caixeta L, Ospina P, Capel M, Nydam D. The association of subclinical hypocalcemia, negative energy balance and disease with bodyweight change during the first 30 days post-partum in dairy cows milked with automatic milking systems. The Veterinary Journal. 2015;204(2):150-6.

48. Galvão KN. Association between immune function and development of uterine disease in dairy cows. Anim Reprod. 2012;9(3):318-22.

49. Østergaard S, Sørensen JT, Houe H. A stochastic model simulating milk fever in a dairy herd. Preventive veterinary medicine. 2003;58(3-4):125-43.

50. Lulie B, Guadu T. Bovine schistosomiasis: a threat in public health perspective in Bahir Dar town, northwest, Ethiopia. Acta Parasitologica Globalis. 2014;5(1):01-6. 
51. Tsega M, Derso S. Prevalence of bovine schistosomiasis and its associated risk factor in and around Debre Tabor town, north west of Ethiopia. Europ J Biol Sci. 2015;7:108-13.

52. Bassazin G, Sewalew M, Birhanu W, Biruk L, Kassay E, . Major Reproductive Health Problems of Dairy Cattles in Gondar Town, Amhara, Ethiopia. Journal of Reproduction and Infertility 2017;8(2):35-43.

53. Thrusfield M. Veterinary epidemiology 3 rd edition Black well science Ltd. London, UK. 2005:32.

54. Gustafsson H, Kornmatitsuk B, Königsson K, Kindahl H. Peripartum and early post partum in the cowphysiology and pathology. MEDECIN VETERINAIRE DU QUEBEC. 2004;34:64-5.

55. Divers TJ, Peek SF. Rebhun's diseases of dairy cattle: Elsevier Health Sciences; 2007.

56. Matthewman RW. Dairying: Macmillan Press Ltd.; 1993.

\section{Figures}

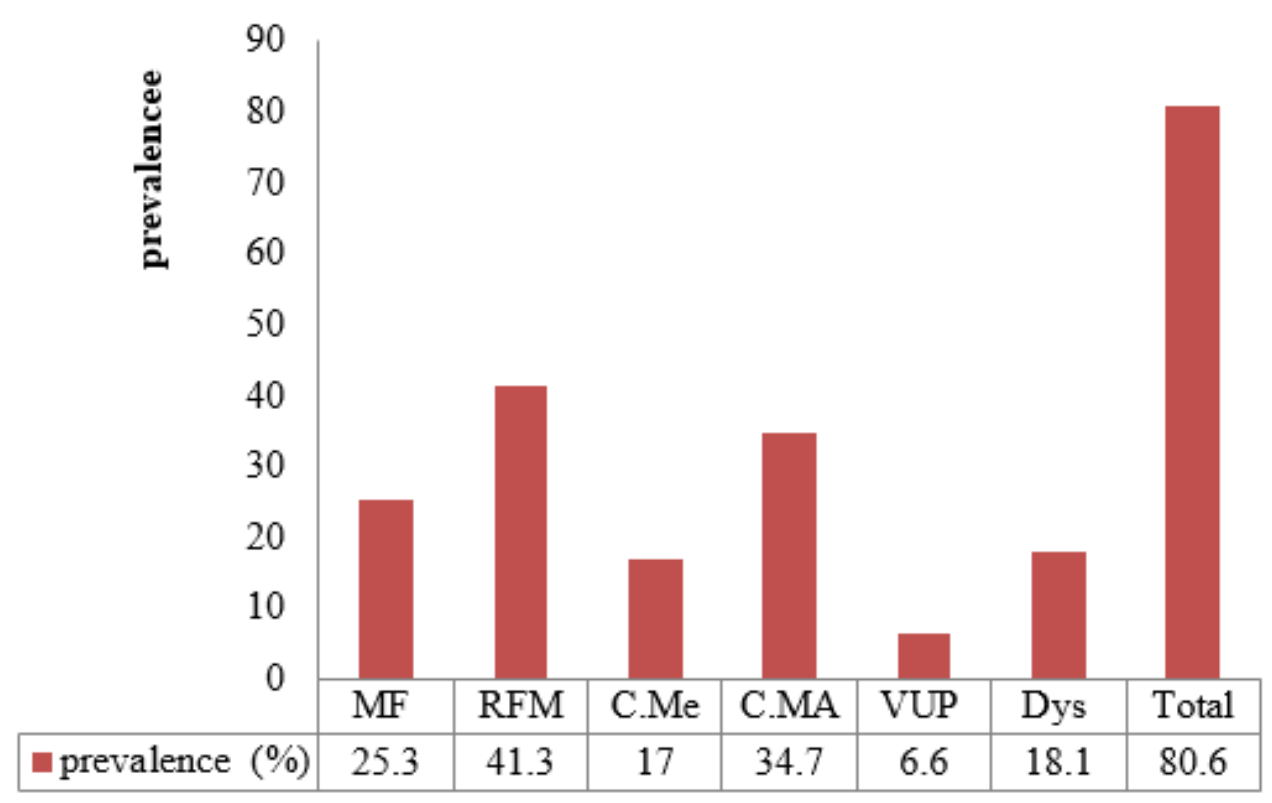

\section{Figure 1}

Herd level prevalence of peri- and early post-partum problems, (MF= Milk Fever, RFM= Retention of Fetal Membrane, $\mathrm{C} . \mathrm{Me}=$ Clinical Metritis, $\mathrm{C} . \mathrm{Ma}=$ Clinical Mastitis, VUP= Vaginal and Uterine Prolapse, Dys =Dystocia) in dairy farms of North-Western Ethiopia. 


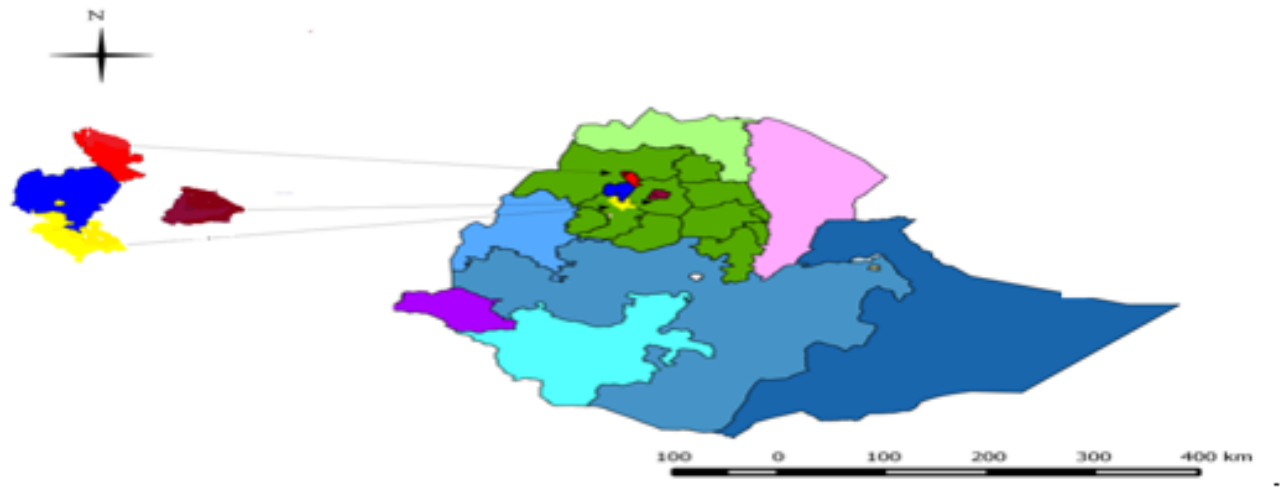

Figure 2

Locational map of the three districts of study area within the country Ethiopia, Gondar (light red), Debre tabor (dark red) and Bahir Dar (Yellow) and the blue color between Gondar and Bahir Dar is Lake Tana. 